\title{
Feasibility Study on the Utilization of Manufactured Sand as a Partial Replacement for River Sand
}

\author{
Dr. B. Vijaya ${ }^{1, a^{*}}$, Dr. S. Senthil Selvan ${ }^{2, b}$ \\ ${ }^{1}$ Associate Professor, Department of Civil Engineering, Dr. M.G.R. Educational and Research \\ Institute, Chennai, Tamilnadu, India \\ 2Professor in Civil Engg, S.R.M. Institute of Science and Technology, Kattankulathur, Chennai, \\ Tamilnadu, India \\ abvijayasuresh@gmail.com, bsenthils10@srmist.edu.in
}

\begin{abstract}
Keywords: River Sand, Manufactured Sand, Soundness Test, EDAX, Modulus of Elasticity, Pull Out Test
\end{abstract}

\begin{abstract}
Continuous extraction of sand is having a huge impact on the natural river beds which has resulted in lowering of water table and a decrease in the amount of sediment supply. Despite the quantity of sand used in our day-to-day activities, our dependence on sand is significantly increasing. The use of manufactured sand as a fine aggregate in concrete draws the attention of many investigators and researchers. The present investigation includes the study of soundness and EDAX .The test results depicted that for M-sand substituted concrete the loss of weight, when subjected to alternate cycles of freezing and thawing when tested with magnesium and sodium sulphate solution was found to be less when compared with natural sand. The important observation is that the inclusion of manufactured sand in concrete reduces the pores present in concrete resulting in matrix densification and makes the concrete impermeable and substantially reduces the rate of oxygen diffusion and reduces the corrosion process as well. This paper also focuses on the effect of manufactured sand as a fine aggregate in the elastic and bond characteristics of concrete.
\end{abstract}

\section{Introduction}

Natural sand tends to be round due to the cumulative effect of multiple collisions and abrasion. Manufactured sand are the product of rock crushing, which creates grains with distinctive particle shapes that depend upon the parent rock composition fracture mode coordination number during crushing, and the reduction ratio. The crushing process tends to produce angular sharp edged particles [1]. The shape and texture of crushed sand particles results in the enhancement of the strength of concrete due to better interlocking between particles[2].However, for the same water content the angular fine aggregate produces mortar of lower workability than spherical sand [3-5], and for the same volume of cement paste [5-7]. Additional water is often incorporated into cement mixtures to enhance the workability, yet higher water content decreases strength, even though there is increase in the inter particle shear resistance[8].

Washing of the micro-fines according to the Chinese national standard JTG F 30-2003 limits the amount of micro-fines to 5\% [9], and it is not feasible to eliminate a portion of them. With the depletion in the river sand supply by over $80 \%$, the necessity for the use of manufactured sand is increasing and is well defined under clause 2 in IS 383-1970 [10].

The bond between concrete and steel enables tensile forces (which concrete has a very low ability to resist) to be transferred to the reinforcement. This steel-concrete bond can be assessed through the bond strength. Bond strength measures the effectiveness of the bond between the 
concrete and the embedded steel. The bond strength is determined by the pull-out test conforming to IS: 2770 (Part I) -1967 [11]. The design accuracy of concrete will depend on the modulus of elasticity of concrete and it was determined as per IS 516-1959 [12].

\section{Sodium sulphate soundness test as per AS 1141.24}

The sodium sulphate and magnesium sulphate soundness test was one of the earliest tests adopted for testing the resistance of aggregates to weathering action. This soundness test was conducted as per AS 1141.24. (1997) [13] to determine the percentage loss of the aggregate which is subjected to a chemical attack. The obtained results of soundness test are presented in Table 1. The aggregate sample preparation is depicted in Figure.1.

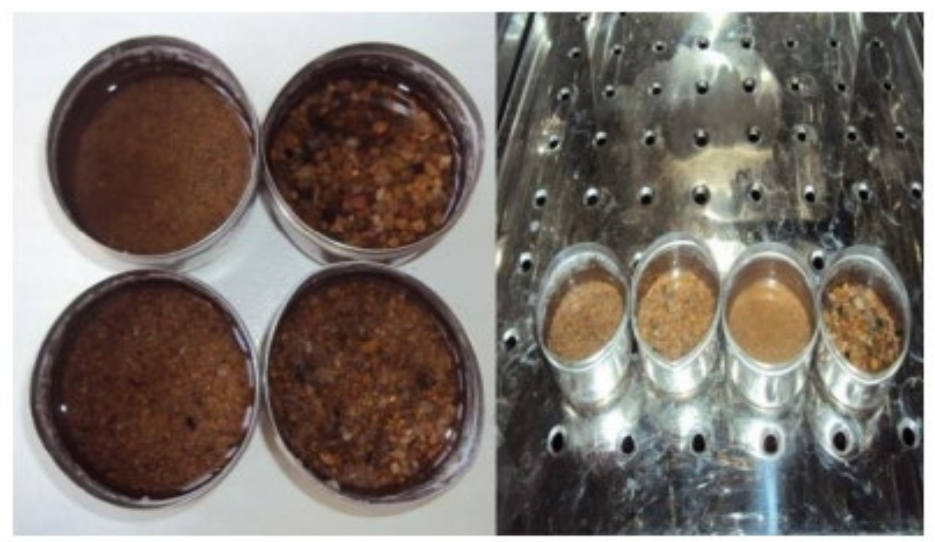

Figure. 1 Aggregate Sample Preparation for Sodium and Magnesium Sulphate Soundness Test

Table 1 Soundness Test

\begin{tabular}{|c|c|c|c|}
\hline Sample & Test conducted & $\begin{array}{c}\text { Result } \\
(\%) \\
\end{array}$ & Remark \\
\hline $\begin{array}{l}\text { Manufactured } \\
\text { sand }\end{array}$ & $\begin{array}{l}\text { The average loss of } \\
\text { weight after } 5 \text { cycles of } \\
\text { freezing and thawing } \\
\text { when tested with Sodium } \\
\text { Sulphate solution. } \\
\text { ( in percentage) }\end{array}$ & 5.79 & \multirow{2}{*}{$\begin{array}{l}\text { The aggregate values shall not exceed } 10 \% \\
\text { and } 15 \% \text { (5cycles) by weight respectively } \\
\text { for aggregate when tested with sodium } \\
\text { sulphate and magnesium sulphate solution } \\
\text { as per IS } 383-1970[10] \text {. }\end{array}$} \\
\hline $\begin{array}{l}\text { Manufactured } \\
\text { sand }\end{array}$ & $\begin{array}{l}\text { The average loss of } \\
\text { weight after } 5 \text { cycles of } \\
\text { freezing and thawing } \\
\text { when tested with } \\
\text { Magnesium Sulphate } \\
\text { solution. } \\
\text { (in percentage) }\end{array}$ & 7.64 & \\
\hline
\end{tabular}


Presence of impurities such as silt, clay in river sand makes it inferior to soundness test when it is subjected to alternate cycles of freezing and thawing when tested with magnesium and sodium sulphate solution and hence the average loss of weight was found as more when compared with M-sand. M-sand as it is manufactured from VSI crusher it is free from deleterious impurities such as silt and clay and hence the loss of weight when is subjected to alternate cycles of freezing and thawing when tested with magnesium and sodium sulphate solution was found to 1.6 and 2 percentage respectively. The percentage loss of weight for M-sand is very less when compared to natural sand. This proves that M-sand is a good and durable material and M-sand may be used for concrete construction works.

\section{EDAX analysis}

EDAX is an energy dispersive analysis done with the help of X-ray which depicts the elemental composition of individual crystals. EDAX is an X-ray system used to identify the basic organization of materials. Peak positions and intensities associated with the pattern are analysed using computers to enable the qualitative analysis. The EDAX shows the various mineral elements present in normal sand and manufactured sand.

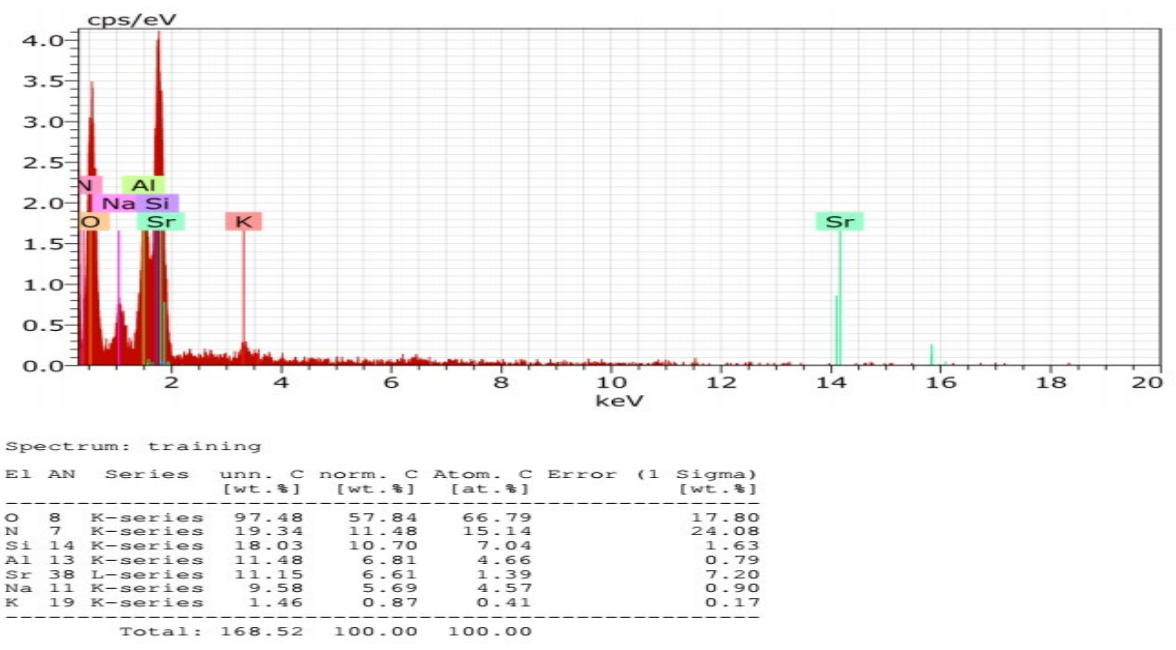

Figure. 2 EDAX Results of River Sand

Figure. 2 shows the EDAX results of river sand. The EDAX of river sand shows the strong peaks for aluminium, silicon, oxygen and weak peaks for strontium, sodium, and potassium. The EDAX seems to have agglomerated expansive gathering of particles of silicon, strontium, oxygen, nitrogen and aluminium. The EDAX clearly shows that there are no traces of iron and calcium particles in river sand but M-sand possesses strong peaks of iron and calcium particles. River sand contains nitrogen, aluminium and potassium elements which are not present in M-sand. There are some regions which appear flattened showing less hydration process. A tangled web of flake-like crystal structure appears due to excess hydration process. The minerals present in river sand form hydrated compounds which give better workability to river sand when compared to M-sand. 

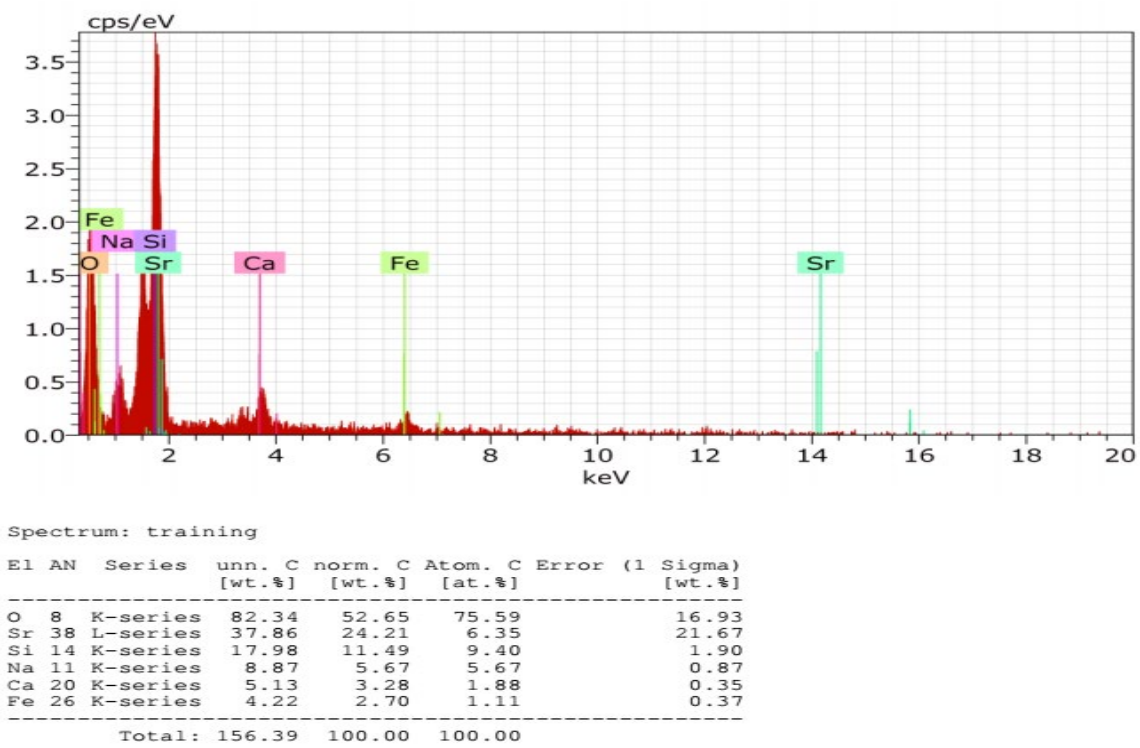

Figure. 3 EDAX Results of Manufactured Sand

Figure.3, shows the EDAX results of manufactured sand. The EDAX of manufactured sand shows the strong peaks for silicon, strontium, oxygen and weak peaks for calcium, iron, sodium. The EDAX seems to have agglomerated expansive gathering of particles of silicon, strontium, oxygen, calcium Iron etc. The extent of coverage is substantial. There are some regions where no hydration had taken place and there is the absence of deposition of hydration products. Some regions illustrate that the hydration process had taken place and there is a change in the appearance of the peaks. There are some regions which show an abundance of hydration products which changes the appearance from small isolated particles to a tangled web of flake-like crystals. The calcium present in $\mathrm{M}$-sand reacts with alumina and oxides and produces tricalcium aluminate which allows early setting and thereby reduces the workability when compared with river sand.

\section{Experimental Investigation}

In the experimental investigation, ordinary Portland cement of 53 grade confirming to IS 12269:2013 [14] and river sand confirming to Zone II of IS 383: 1970 [10] was used. Mix design was carried out based on IS 10262:2009 [15] for M30 grade with 0.45 W/C and ratio 1:1.70:2.70. From the experimental results, the increase in the percentage of manufactured sand increases the compressive strength up to $60 \%$ substitution of manufactured sand for river sand, beyond which there is a decrease in compressive strength and it was concluded that the optimum percentage of substitution of manufactured sand is taken as $60 \%[16,17]$. The modulus of elasticity and the bond strength behaviour were dertermined for $60 \% \mathrm{M}$-sand substituted concrete.

\section{Bond Strength}

Twenty eight cylindrical specimens of size $300 \mathrm{~mm}$ in length and $150 \mathrm{~mm}$ in diameter were cast with embedded high strength deformed (HYSD) bar of $16 \mathrm{~mm}$ in diameter placed at the centre to determine the bond strength behaviour of concrete. Figure 4.shows the casting, curing and testingof the specimens for the bond strength. 
Table 2 Average Bond Strength Values of Conventional and M-Sand Concrete

\begin{tabular}{|c|c|c|}
\hline SI.No & Mix Identification & Average Bond Strength (MPa) \\
\hline 1 & M30-Conventional & 7.82 \\
\hline 2 & M30-M-sand (60\%) & 9.72 \\
\hline
\end{tabular}
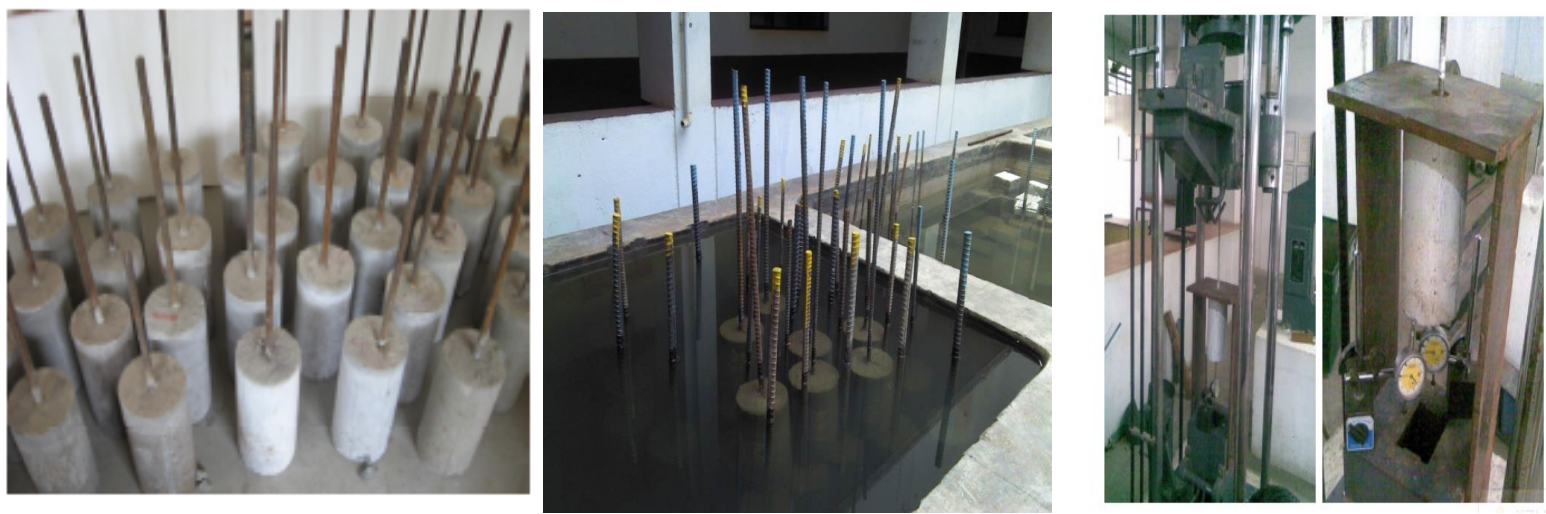

Figure 4 Casting, curing and testing of the Specimen for the Bond Strength Test

From the Table 2, it is proved that the average bond strength tends to increase with respect to the inclusion of M-sand in concrete. The proper gradation of M-sand obtained through the VSI crusher, the angular nature of the M-sand particles and the rough surface texture improves the inner friction within the mix and creates better interlocking between the M-sand particles and the rebar which increases the bond characteristics.

\section{Modulus of Elasticity}

Modulus of Elasticity is a necessary parameter to determine the stresses in materials and structures. Even though concrete has nonlinear stress-strain behaviour, modulus of elasticity is important material property to design and analyse concrete structures. The design accuracy of concrete will depend on the modulus of elasticity of concrete and it was determined as per IS $516-1959$ [12] by subjecting a cylindrical specimen of size $150 \mathrm{~mm}$ in diameter and $300 \mathrm{~mm}$ in height to uniaxial compression in server control UTM. The deformations are measured by means of dial gauges fixed between certain gauge length. The strain is measured by dividing the dial gauge reading with the gauge length and the applied load divided by the area of cross section of the cylindrical specimen will give the corresponding stress. This change in stress with respect to the elastic strain gives the modulus of elasticity of concrete. The experimental values of $\mathrm{E}$ were obtained from the slopes of the corresponding stress-strain curves. The theoretical values of $\mathrm{E}$ were calculated as per IS 456: 2000 [18]. The calculated values of E are compared with the experimental values and are tabulated in Table 3

Table 3 shows the E values of control concrete and 60\% M-sand concrete. As the percentage substitution of manufactured sand is increased, the value of modulus of elasticity also increased. The experimental investigation showed that the M30 grade concrete with $60 \% \mathrm{M}$-sand substitution has the higher modulus of elasticity value than the conventional The modulus of elasticity 
increased by $11.92 \%$ for the M30 grade of concrete when replaced with $60 \% \mathrm{M}$-sand. The experimental values of $\mathrm{E}$ were found to be more than the theoretical values by $6.53 \%$ and $4.53 \%$ for M30 control concrete and for $60 \%$ manufactured sand substituted concrete respectively. From the experimental investigation, it was found that the experimental values of $\mathrm{E}$ is more than the theoretical values for control concrete and manufactured sand substituted concrete. It was clear from the results that the addition of $\mathrm{M}$-sand had improved the modulus of elasticity of concrete.

Table 3 The average Characteristic Compressive Strength and Modulus of Elasticity of Concrete incorporating M-sand

\begin{tabular}{|c|c|c|c|c|c|}
\hline \multirow{2}{*}{ SI.No } & Mix Identification & \multirow{2}{*}{\begin{tabular}{c} 
Characteristic \\
Compressive \\
\cline { 4 - 6 }
\end{tabular}} & Strength (MPa) & \multicolumn{3}{|c|}{ Modulus of elasticity, E (MPa) } \\
\cline { 4 - 6 } & Experimental & Theoretical & $\begin{array}{c}\text { Expt./ } \\
\text { Theo. }\end{array}$ \\
\hline 1 & M30- Conventional & 36.12 & 32149.87 & 30049.95 & 1.06 \\
\hline 2 & M30-M-sand (60\%) & 47.20 & 35982.26 & 34351.12 & 1.04 \\
\hline
\end{tabular}

\section{Conclusion}

- Incorporation of manufactured sand improves the bond characteristics of concrete. The proper gradation of M-sand obtained through the VSI crusher, the angular nature of the $\mathrm{M}$-sand particles and the rough surface texture improves the inner friction within the mix and creates better interlocking between the M-sand particles and the rebar which increases the bond characteristics.

- The soundness test results for river sand and manufactured sand are within the permissible limits as specified in IS 383-1970.

- The EDAX results of river sand shows that the minerals present in river sand forms hydrated compounds which gives good workability for river sand when compared with M-sand.

- It was also concluded that the development length of the rebar can be reduced, when $\mathrm{M}$-sand is used in construction, which consequently reduces the economy in construction.

- The modulus of elasticity increase with the addition of M-sand in concrete due to the rough surface nature and the angular particles of manufactured sand creates better bonding between the hydrated cement paste and the aggregate.

- In general manufactured sand can be used as an efficient and effective alternative for river sand in concrete.

\section{References}

[1] H.Donza,O. Cabrera, E.F. Irassar, High-strength concrete with different fine aggregate , Cement and Concrete Research 32 (11) (2002) 1755-1761.

https://doi.org/10.1016/S0008-8846(02)00860-8 
[2] P. Quiroga, D. Fowler, The effects of aggregates characteristics on the performance of Portland cement concrete, International center for aggregates research 104-1F .

[3] S.Jamkar, C.Rao, Index of aggregate particle shape and texture of coarse aggregate as a parameter for concrete mix proportioning, cement and concrete research 34 (11) (2004) 2021-2027. https://doi.org/10.1016/j.cemconres.2004.03.010

[4] M.Westerholm, Rheology of the mortar phase of concrete with crushed aggregate, Department of chemical engineering and Geosciences, Licentiate, vol.198, Lulea University of technology, Stockholm, 2006.

[5] F.I. Mel'nikov, calculation methods for determining compositions of refractory concretes, refractories and industrial ceramics 11 (1970) 591-595. https://doi.org/10.1007/BF01290553

[6] H.Jarvenpaa, Quality characteristics of fine aggregates and controlling their effects on concrete, department of materials science and rock engineering, Helsinki University of technology, Doctor of Thechnology, vol.243, 2001.

[7] M.F. Kalpan, Flexural and compressive strength of concrete as affected by the properties of a coarse aggegrates,American Concrete Institute 55 (1959) 1193 - 1208.

[8] JTG F 30-2003, Technical specification for construction of highway cement concrete pavements. Beijing; Ministry of transport of the People's Republic of China: 2003.

[9] Ahn N, Experimental study on the guidelines for using higher contents of aggregate micro fines in Portland cement concrete . Ph.D.Thesis. University of Texas.

[10] IS: 383 (1970, Reaffirmed: 2002), Code of Practice: Specification for Coarse and Fine Aggregates from Natural Sources for Concrete, Bureau of Indian Standards, New Delhi.

[11] IS: 2770 (Part I)-1967 "Methods of testing bond in reinforced concrete," BIS, New Delhi.

[12] IS:516-1959, Recommended guidelines for concrete mix, Bureau of Indian Standards, New Delhi.

[13] AS 1141.24, (1997) "Methods for sampling and testing aggregates-Aggregate soundness," Evaluation by exposure to sodium sulfate solution.

[14] IS 12269 : 2013 Code of Practice: Ordinary Portland Cement, 53 Grade - Specification

[15] IS:10262-1982, Recommended guidelines for concrete mix, Bureau of IndianStandards, New Delhi.

[16] Vijaya. B and Senthil Selvan.S,Comparative Study on the Strength and Durability Properties of Concrete with Manufactured sand, Indian Journal of Science and Technology, (2015), 8(36),.1-7. https://doi.org/10.17485/ijst/2015/v8i36/88614

[17] Vijaya, B and Senthil Selvan. S.,Experimental Investigation on the strength and Durability properties of concrete using Manufactured sand, " International Journal of Applied Engineering Research , International Journal of Applied Engineering Research, (2015), 10 (68), 109-114.

[18] IS 456 (2000), - Code of Practice for Plain and Reinforced Concrete, Bureau of Indian Standards, New Delhi. 